\title{
Pembinaan Tubuh Wanita di Iklan Julia Perez
}

\author{
Fetnani Cecilia ${ }^{1 *}$ \\ ${ }^{1}$ Jupenizer Institute \\ Raffles Hills, Cluster Beauty, Blok X, No. 6, Jakarta Timur, 13720, Indonesia \\ ${ }^{(*)}$ Corresponding Author: feycenna@gmail.com
}

\begin{abstract}
Kajian ini bertujuan untuk mencari pembinaan bentuk badan perempuan dalam iklan Julia Perez termasuk Ya Ya Susu Kopi 'dan ar Sari Sari Susu Soda'. Data dikumpulkan menggunakan pendekatan kualitatif deskriptif yang kemudian dianalisis dengan menggunakan teori semiotik Roland Barthes. Keputusan yang diperolehi mendedahkan bahawa iklan Julia Perez dan Kopi Susu Ya! 'Dan ar Segar Sari Susu Soda' mengandung unsurunsur ideologi patriarki yang muncul melalui adegan dan visualisasi gambar. Melalui karya ini ia telah mendedahkan bahawa imej ideal wanita dalam iklan telah dibina berdasarkan perspektif lelaki. Oleh itu, wanita ideal adalah wanita yang mempunyai kulit licin, perut tipis, payudara besar, punggung besar, dan panjang, rambut lurus. Ini bermakna wanita yang tidak memenuhi kriteria ini dianggap wanita yang tidak sesuai atau tidak menarik bagi lelaki.
\end{abstract}

Keywords : Ideologi patriarki; Julia Perez; Teori Semiotik; Perwakilan Wanita; 


\section{REFERENCES}

Setiawan, Adib Rifqi. (2013). Menjilati Yuli: tegap menghibur walau dalam tangis. Alobatnic.blogspot.com, July 15. Accessed from http://alobatnic.blogspot.com.blogspot.com/2013/07/yuli.html

Setiawan, Adib Rifqi. (2014). Membaca Julia: karya biasa saja dari yuli rachmawati. AdibRS.blogspot.com, July 15. Accessed from https://adibrs.blogspot.com/2014/10/julia.html

Setiawan, Adib Rifqi. (2016). Dari Yuli Hingga Julia: memuji yuli, memuja julia. AdibRS.blogspot.com, July 15. Accessed from https://adibrs.blogspot.com/2016/07/yuli.html

Setiawan, Adib Rifqi. (2017a). Butcah Chuniez. Alobatnic.blogspot.com, February 15. Accessed from https://adibrs.blogspot.com/2017/02/thata.html

Setiawan, Adib Rifqi. (2017b). Hope, Faith, Love: A Brief Story of Yuli Rahmawati. Alobatnic.blogspot.com, July 15. Accessed from http://alobatnic.blogspot.com.blogspot.com/2017/07/hope-faith-love.html

Setiawan, Adib Rifqi. (2018a). Julia Perez — Iklan Ya Kopi Susu. YouTube.com/AdibRS, January 26. Accessed from https://youtu.be/3qpRGihySTw

Setiawan, Adib Rifqi. (2018b). Julia Perez — Iklan Segar Sari Susu Soda. YouTube.com/AdibRS, January 26. Accessed from https://youtu.be/ENjh17AvCsI

Setiawan, Adib Rifqi. (2018c). Ki Oza Kioza. Alobatnic.blogspot.com, March 1. Accessed from http://alobatnic.blogspot.com.blogspot.com/2018/03/roza-lailatul-fitria-oza-kioza.html

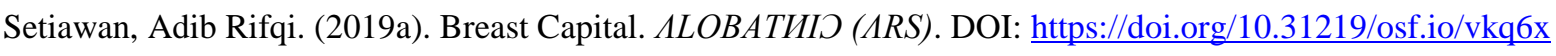

Setiawan, Adib Rifqi. (2019b). Pantat Perekat Umat. ALOBATИID (LRS). DOI: https://doi.org/10.31219/osf.io/m5qdv

Zein, Laila Fariha, \& Setiawan, Adib Rifqi. (2019a). Julia Perez: une authentique modèle. Scholaristi. DOI: https://doi.org/10.31227/osf.io/br9vt

Zein, Laila Fariha, \& Setiawan, Adib Rifqi. (2019b). Kajian Semiotika Terhadap Lagu Julia Perez. Scholaristi. DOI: https://doi.org/10.31227/osf.io/pevgb

Zein, Laila Fariha, \& Setiawan, Adib Rifqi. (2019c). Salahkah Menjadi Perempuan Cantik?. Scholaristi. DOI: https://doi.org/10.31227/osf.io/65bdt

Zein, Laila Fariha. (2019a). Risalah Sampah. LAILA. DOI: https://doi.org/10.31227/osf.io/ykqrm

Zein, Laila Fariha. (2019b). Muslimah Idaman Sepanjang Zaman. LAILA. DOI: https://doi.org/10.31227/osf.io/e5pnv

Zein, Laila Fariha. (2019c). Harmoni Cinta Untuk Semesta. LAILA. DOI: https://doi.org/10.31227/osf.io/2gmnz 